\title{
Correction
}

\section{Correction to: From Liverpool to Beijing and Chongqing: William Band's Adventure in Wartime China}

Danian $\mathrm{Hu}^{*}$

\section{Correction to: Phys. Perspect. https://doi.org/10.1007/s00016-019-00241-0}

Dear readers,

In the original publication of this article, the author noticed some minor errors. In the caption of Fig. 7, the name "Y. K. Hs" should be changed to "Y. K. Hsü". Page 5: at the end of 2nd paragraph under the Note number "16"), there is a superfluous comma (",") that should be deleted.

We apologize for these errors.

\author{
Department of History, The City College of New York \\ 160 Convent Avenue \\ New York, NY 10031, U.S.A. \\ e-mail: danian.hu@aya.yale.edu
}

* The original article can be found online at https://doi.org/10.1007/s00016-019-00241-0. 